26(1), 187-200

\title{
Study on a Hedging Volatility Depending on Path Type of Underlying Asset Prices
}

\author{
Jeongbon $\mathrm{Koo}^{a} \cdot$ Junmo Song ${ }^{b, 1}$ \\ ${ }^{a}$ HMC Investment Securities, Over-the-Counter Derivative Team \\ ${ }^{b}$ Department of Computer Science and Statistics, Jeju National University \\ (Received August 3, 2012; Revised December 7, 2012; Accepted January 24, 2013)
}

\begin{abstract}
In this paper, we deal with the problem of deciding a hedging volatility for ATM plain options when we hedge those options based on geometric Brownian motion. For this, we study the relation between hedging volatility and hedge profit\&loss $(\mathrm{P} \& \mathrm{~L})$ as well as perform Monte Carlo simulations and real data analysis to examine how differently hedge $\mathrm{P} \& \mathrm{~L}$ is affected by the selection of hedging volatility. In conclusion, using a relatively low hedging volatility is found to be more favorable for hedge P\&L when underlying asset prices are expected to be range bound; however, a relatively high volatility is found to be favorable when underlying asset prices are expected to move on a trend.
\end{abstract}

Keywords: Hedging volatility, ATM plain option, delta hedge, gamma, hedge error, hedge profit and loss.

\section{1. 서론}

Black과 Scholes (1973)가 기하브라운 운동(geometric Brownian motion; GBM)을 기반으로 표준옵 션(plain option)의 가격 공식을 유도한 이후, $\mathrm{GBM}$ 은 다양한 금융자산의 가격 움직임(dynamics)을 모 형화 하는데 널리 이용되었다. 그러나, 1987년 블랙먼데이(Black Monday) 이후 금융시장의 불안정성 이 증대되고 변동성의 움직임이 불규칙해지면서, 고정된 변동성을 가정한 $\mathrm{GBM}$ 은 현실적인 한계에 부 딪히게 되었고, 이와 관련된 사례들은 다수의 실증연구들을 통하여 보고되었다. 이에 따라, GBM모 형의 단점을 보완하기 위한 연구들이 진행되었는데, Dupire (1994)와 Elder (2002) 등은 국소변동 성 모형(local volatility model)을 통하여, Heston (1993) 및 Hull과 White (1987) 등은 확률변동 성 모형(stochastic volatility model)을 통하여 모형을 발전시켰으며, 이 외에도 점프를 포함한 레비 과정(Levy processes) 등을 이용한 모형들이 속속 개발되었다 (Cont와 Tankov, 2004).

하지만, 새로운 모형들이 학계에서 꾸준히 개발되고 있음에도 불구하고, 모수 추정과 구현의 용이성으 로 인하여 현장 실무에서는 $\mathrm{GBM}$ 이 여전히 애용되고 있다. GBM모형이 실제 주가의 움직임과 차이가 있음에도, 주가가 GBM을 따른다는 가정 하에 파생상품의 가격을 계산하고 이를 바탕으로 헤지(hedge)

This paper is mainly based on the Master's thesis of the first author in financial economics at Yonsei University.

${ }^{1}$ Corresponding author: Assistant professor, Department of Computer Science and Statistics, Jeju National University, 102 Jejudaehakno, Jeju-si, Jeju-do 690-756, Korea. E-mail: jmsong@jejunu.ac.kr 
매매를 수행하는 것이다. 사용하고 있는 기초자산의 가격모형이 실제 가격의 움직임과 비슷할수록 이를 기반으로하는 헤지모형의 오차는 작아지기 때문에, 앞서 언급한 연구들은 현실적인 모형을 개발함으로 써 헤지오차(hedge error)를 최소화하는데 초점을 두었다고 할 수 있다.

한편, 기초자산의 가격이 GBM을 따른다는 가정 하에 파생상품 또는 파생결합증권의 헤지를 수행하는 경우, 헤저(hedger)의 최대 관심사는 파생상품의 잔존기간 동안 실현될 변동성의 예측에 있게 된다. 매 매의 목적이 파생상품의 헤지 그 자체에 있다면, 매매자는 모든 정보를 이용하여 향후 변동성을 예측 하고, 예측된 변동성을 바탕으로 헤지매매를 수행하게 된다. 즉, 예측된 변동성을 헤지변동성(hedging volatility)으로 사용하여 매매해야할 기초자산의 수량을 계산하는 것이다. 기초자산의 실제 움직임이 $\mathrm{GBM}$ 과 큰 차이가 없고 실현된 변동성이 예측된 변동성과 비슷할 경우 예상할 수 있는 오차 범위 내에 서 혜지가 가능하게 되지만, 기초자산의 실제 움직임은 가정한 모형과 차이를 보일 때가 많고 향후 변동 성에 대한 예측 또한 쉽지 않기 때문에 파생상품의 헤지는 일정 수준 이상의 헤지오차를 수반하는 경우 가 많다. 이러한 헤지오차는 상품 판매 시 수수료에 포함시키거나, 적극적인 운용에 의한 추가 수익(이 하, $+\alpha$ )을 통하여 그 비용을 보전하기도 한다. 비단 이런 상황이 아니더라도 실무에서의 헤지 매매자는 정확한 헤지(또는 복제) 그 자체보다는 매 순간 $+\alpha$ 를 추구하려는 경향이 높은데, 이러한 경우 미리 정 해진 리스크 한도 내에서 스팩(speculation)에 의한 매매가 종종 발생하게 된다. 기초자산의 방향성에 배팅하여 계산된 헤지수량보다 더 많거나 혹은 적게 기초자산을 매매하거나, 변동성에 베팅하여 예상되 는 변동성보다 더 크거나 작은 값을 혜지변동성으로 결정하여 매매를 수행하는 경우 등이 그 예가 된다.

본 논문에서는 GBM모형으로 델타(delta) 헤지를 수행하는 경우 $+\alpha$ 를 위한 헤지변동성의 결정에 대 하여 연구한다. 구체적으로, 표준옵션(plain option)의 헤지매매 시 기초자산의 추세 여부가 예상될 때, 이에 따른 헤지변동성의 선택 기준에 대하여 다루고자 한다. 이는 현업의 실무자들이 관심을 갖는 지극 히 현실적인 문제로서, 헤지변동성과 혜지손익과의 관계 혹은 델타헤지의 효율성과 관련되어 있다. 이 러한 연구들로 Derman (2008)은 GBM 하에서의 헤지손익과 변동성과의 관계를 설명하였고, Crépey (2004)는 GBM과 국소변동성 모형 하에서의 헤지손익에 대한 비교 연구를 하였으며, Primbs와 Yamada (2008), Kennedy 등 (2009)와 Sepp (2012) 등은 거래비용을 고려한 상태에서의 델타헤지의 손 익에 대한 연구를 수행하였다. 특히, 본 논문의 연구 내용은 Gatheral (1999)의 Merrill Lynch 보고서 에서 다루어졌던 것으로, 그의 연구에서는 기초자산 가격의 횡보, 즉 특별한 방향성 없이 가격이 진행되 는 상태가 예상될 때에는 헤지변동성을 크게, 추세가 예상될 때에는 작게 사용하는 것이 헤지손익에 유 리함을 보고하였다. 하지만, 이 보고서에는 결론을 뒷받침할만한 분석과정과 통계적 검증 절차가 수행 되지 않았기에 본 논문에서는 헤지변동성과 헤지손익과의 관계를 살펴보고, 보다 다양한 주가 형태를 고 려한 모의실험을 통하여 기초자산의 추세 유무와 이에 따른 헤지변동성의 선택이 헤지손익에 미치는 영 향을 재탐색하고자 한다.

본 논문의 구성은 다음과 같다. 2 장에서는 델타헤지(delta hedge) 수행 시 헤지변동성과 헤지손익과의 관계에 대하여 살펴보고, 3 장에서는 주가경로의 형태에 따른 혜지변동성과 헤지손익의 관계를 모의실험 을 통하여 살펴본다. 그리고 4장에서는 KOSPI200 지수에 대한 실증분석을 수행하고, 마지막 5 장에서 는 본 논문의 결론과 실무에서의 활용 방안 등에 대하여 언급한다.

\section{2. 옵션의 델타헤지와 헤지손익}

2.1절에서는 블랙-솔즈 가정 하에서의 옵션의 델타헤지에 대하여 소개한다. 이 내용을 바탕으로, 실제 주가의 움직임과는 상관없이 $\mathrm{GBM}$ 을 가정하여 헤지를 수행하는 경우의 헤지손익의 형태를 2.2 절에서 살펴본다. 2.2 절의 정리들은 Derman (2008)의 2 장에서 발견할 수 있으나, 본 논문에서는 그 결과들을 다른 방식으로 유도해본다. 편의상 옵션매도 포지션에 대한 헤지를 기준으로 설명한다. 


\section{1. 파생상품의 델타헤지}

옵션 매도 포지션의 헤지는 옵션의 만기 수익구조(payoff)를 복제하는 것을 의미한다. 만기시점에서의 옵션의 이론가격은 만기수익과 같기 때문에, 옵션의 복제는 헤지 시점마다 헤지모형에서 유도된 옵션 이 론가격의 변화량을 다양한 금융자산의 매매 또는 거래를 통하여 만들어냄으로써 이루어진다. 즉, 옵션 의 복제는 옵션의 이론 가격을 추종함으로써 이루어지는 것이다.

블랙-솔즈 가정 하에서, 옵션 이론가격의 순간적인 변화량은 Taylor 전개에 의하여 다음과 같이 표현될 수 있다.

$$
d f_{t}=\partial_{s} f_{t} d S_{t}+\frac{1}{2} \partial_{s s}^{2} f_{t}\left(d S_{t}\right)^{2}+\partial_{t} f_{t} d t
$$

여기서 $f_{t}$ 와 $S_{t}$ 는 $t$ 시점에서의 옵션의 이론가격과 기초자산의 가격이고 $\partial_{x}$ 는 $x$ 에 대한 1 차 미분을 $\partial_{x x}^{2}$ 은 2 차 미분을 나타낸다.

위 식에서 알 수 있듯이, 옵션 가격의 변화량은 기초자산 가격의 변화에 의한 부분 $\partial_{s} f_{t} d S_{t}, \partial_{s s}^{2} f_{t}\left(d S_{t}\right)^{2}$ 과 시간의 흐름에 의한 부분 $\partial_{t} f_{t} d t$ 들로 분해된다. 델타헤지란 헤지 시점마다 $\partial_{s} f_{t}$ (이하, $\Delta_{t}$ )개의 기초 자산을 보유함으로써 옵션 이론가격의 변화량 중 $\partial_{s} f d S_{t}$ 에 해당하는 금액을 만들어 내는 것을 의미한 다. 델타헤지를 수행하는 경우 헤지 포트폴리오는 일반적으로 $\Delta$ 개의 기초자산과 특정 이자율(무위험 이자율)로 차입(borrowing)과 대출(lending)이 가능한 단기금융상품(money market fund; MMF)들 로 구성되는데, 기초자산의 변동성과 무위험 이자율이 변하지 않을 경우, 연속적인 포트폴리오의 재조 정(rebalancing)을 통하여 옵션의 만기 수익구조를 복제할 수 있다. 이를 확인하기 위하여 $t$ 시점에서 $\Delta_{t}$ 개의 기초자산과 $\left(f_{t}-\Delta_{t} S_{t}\right)$ 금액에 해당하는 $\mathrm{MMF}$ 로 구성된 포트폴리오를 생각하고, 이 포트폴리 오의 가격을 $P_{t}$ 라고 하자. 블랙-숄즈 가정 하에서 $\left(d S_{t}\right)^{2}$ 은 불확실성 (randomness)이 사라진 상태가 되 므로, 시장에 차익(arbitrage)거래 기회가 존재하지 않는다면, 식 (2.1)로부터 옵션 1개를 보유하고 기 초자산 $\Delta_{t}$ 개를 공매한 포트폴리오의 가격의 순간변화량은 $\left(f_{t}-\Delta_{t} S_{t}\right)$ 금액에 해당하는 $\mathrm{MMF}$ 가격의 순간변화량 $r\left(f_{t}-\Delta_{t} S_{t}\right) d t$ 와 같게 된다(Black-Scholes equation):

$$
d f_{t}-\Delta_{t} d S_{t}=\frac{1}{2} \partial_{s s}^{2} f_{t}\left(d S_{t}\right)^{2}+\partial_{t} f_{t} d t=r\left(f_{t}-\Delta_{t} S_{t}\right) d t .
$$

한편, 헤지 포트폴리오 가격 $P_{t}$ 의 순간변화량은

$$
d P_{t}=\Delta_{t} d S_{t}+r\left(f_{t}-\Delta_{t} S_{t}\right) d t
$$

이므로, 식 (2.2)로부터 확률 1(with probability 1)로 $d P_{t}=d f_{t}$ 가 성립한다. 따라서 $\Delta_{t}$ 개의 기초자산 과 $\left(f_{t}-\Delta_{t} S_{t}\right)$ 금액의 $\mathrm{MMF}$ 로 포트폴리오를 연속적으로 조정할 수 있을 경우 헤지 포트폴리오의 가격 은 옵션의 가격과 일치하게 되어 만기시점에서 옵션의 payoff를 만들어낼 수 있게 된다. 하지만 실제 델 타헤지는 위 가정 하에서 이루어지지 않는다. 포트폴리오의 조정은 연속적으로 이루어질 수 없으며, 기 초 자산의 변동성 또한 시간의 흐름에 따라 많은 경우 변하게 된다. 현실과 가정의 이러한 괴리는 헤지 시점마다 헤지오차, 즉 옵션의 가격변화량과 헤지포트폴리오의 가격변화량의 차이를 발생시키고, 헤지 오차가 누적되면서 헤저의 최종 헤지손익이 결정되게 된다. 특히 변동성과 관련하여, 향후 실현될 변동 성을 알수 없기 때문에 블랙-솔즈 가정을 기반으로 하는 델타헤지는 헤지변동성의 선택에 따라 최종 손 익이 크게 좌우된다.

\section{2. 헤지변동성과 헤지손익}

헤지변동성의 선택에 따른 헤저의 최종 손익을 살펴보기 위하여, 기초자산의 가격이 다음의 확률미분방 
정식을 따른다고 가정하자.

$$
d S_{t}=\mu S_{t} d t+\sigma_{t} S_{t} d W_{t},
$$

여기서 $\left\{W_{t}\right\}$ 는 표준 브라운 운동(standard Brownian motion)이고 $\sigma_{t}$ 는 $t$ 시점에서의 순간변동성이다. 그리고 혜저는 블랙-솔즈 가정 하에 연속적으로 델타헤지를 수행한다고 하자. 즉, 헤저는 옵션의 잔존기 간 동안 고정된 헤지변동성을 사용하여 기초자산의 매매 수량을 계산하며 매 순간마다 포트폴리오를 재 조정한다.

헤저의 헤지변동성을 $\sigma_{H}$ 라하고 이 변동성에 의하여 계산된 $t$ 시점에서 옵션의 이론가격과 델타를 각각 $f_{t}^{H}, \Delta_{t}^{H}$ 라고 하자. 옵션은 $f_{0}^{H}$ 의 가격으로 매도된 것으로 간주한다. 최초 헤지 포트폴리오는 $\Delta_{0}^{H}$ 개의 기초자산과 $\left(f_{0}^{H}-\Delta_{0}^{H} S_{0}\right)$ 금액의 $\mathrm{MMF}$ 로 구성되고, $t$ 시점에서는 $\Delta_{t}^{H}$ 개의 기초자산과 $\left(f_{t}^{H}-\Delta_{t}^{H} S_{t}\right)$ 금 액의 $\mathrm{MMF}$ 가 되도록 재조정한다. 이제 이 포트폴리오의 가격을 $P_{t}^{H}$ 라 하면, $P_{t}^{H}$ 의 순간적인 변화량은 다음과 같게 된다.

$$
d P_{t}^{H}=\Delta_{t}^{H} d S_{t}+r\left(f_{t}^{H}-\Delta_{t}^{H} S_{t}\right) d t
$$

헤저는 주가과정이 식 (2.3)이 아닌 확률미분방정식 $d S_{t}^{H}=\mu S_{t} d t+\sigma_{H} S_{t} d W_{t}$ 를 따른다는 가정 하에 헤지를 수행하고 있으므로, $t$ 시점에 실제 주가 $S_{t}$ 가 관찰되었을 때 $\left(d S_{t}^{H}\right)^{2}$ 은 $\sigma_{H}^{2} S_{t}^{2} d t$ 로 가정하게 된다. 따라서, 식 (2.2)에서와 같은 방법에 의해

$$
\begin{aligned}
r\left(f_{t}^{H}-\Delta_{t}^{H} S_{t}\right) d t & =\frac{1}{2} \partial_{s s}^{2} f_{t}^{H}\left(d S_{t}^{H}\right)^{2}+\partial_{t} f_{t}^{H} d t \\
& =\frac{1}{2} \partial_{s s}^{2} f_{t}^{H} \sigma_{H}^{2} S_{t}^{2} d t+\partial_{t} f_{t}^{H} d t
\end{aligned}
$$

가 되므로,

$$
d P_{t}^{H}=\Delta_{t}^{H} d S_{t}+\frac{1}{2} \partial_{s s}^{2} f_{t}^{H}\left(\sigma_{H}\right)^{2} S_{t}^{2} d t+\partial_{t} f_{t}^{H} d t
$$

가 된다.

그리고, $f_{t}^{H}$ 의 순간변화량은 식 (2.3)을 따르는 실제 주가과정의 순간변화량에 의해 결정되므로

$$
\begin{aligned}
d f_{t}^{H} & =\Delta_{t}^{H} d S_{t}+\frac{1}{2} \partial_{s s}^{2} f_{t}^{H}\left(d S_{t}\right)^{2}+\partial_{t} f_{t}^{H} d t \\
& =\Delta_{t}^{H} d S_{t}+\frac{1}{2} \partial_{s s}^{2} f_{t}^{H} \sigma_{t}^{2} S_{t}^{2} d t+\partial_{t} f_{t}^{H} d t
\end{aligned}
$$

가 된다. 그러므로, $t$ 시점에서 헤지 포트폴리오의 가격과 옵션 이론가격의 순간적인 차이는

$$
d P_{t}^{H}-d f_{t}^{H}=\frac{1}{2} \partial_{s s}^{2} f_{t}^{H}\left[\sigma_{H}^{2}-\sigma_{t}^{2}\right] S_{t}^{2} d t
$$

가 되고, 따라서 헤저의 최종 손익은 다음과 같게 된다.

$$
P_{T}^{H}-f_{T}=P_{T}^{H}-f_{T}^{H}=\frac{1}{2} \int_{0}^{T} \partial_{s s}^{2} f_{t}^{H}\left[\sigma_{H}^{2}-\sigma_{t}^{2}\right] S_{t}^{2} d t,
$$

여기서 $T$ 는 옵션의 만기이고 $P_{0}^{H}=f_{0}^{H}$ 이며, $f_{T}$ 는 만기시점에서의 옵션의 실제 가격이다.

현실에서의 혜지 포트폴리오의 재조정은 불연속적으로 이루어지므로, 최종 손익은 식 (2.4)를 이산화함 으로써 근사적으로 얻어진다. 기초자산의 매매 시 발생하는 수수료 및 세금 등의 비용이 없는 것으로 간 주할 경우, 헤저의 근사 손익은 다음과 같다. 
정리 2.1 주가과정 $\left\{S_{t}\right\}$ 가 식 (2.3)을 따른다고 하자. 헤지변동성 $\sigma_{H}$ 로 옵션이 매도되었을 경우, 델타헤지를 수 행하는 헤저의 최종 손익은 다음과 같다.

$$
P_{T}^{H}-f_{T} \approx \frac{1}{2} \sum_{i=0}^{n-1} \Gamma_{i}^{H}\left[\sigma_{H}^{2}-\sigma_{t_{i}}^{2}\right] S_{i}^{2}\left(t_{i+1}-t_{i}\right),
$$

여기서 $t_{0}$ 는 옵션의 매매시점, $t_{i}$ 는 $i$ 번째 헤지(재조정) 시점, $t_{n}(=T)$ 는 옵션의 만기시점이고, $S_{i}$ 와 $\Gamma_{i}^{H}$ 는 $t_{i}$ 시점 에서의 주가와 $\partial_{s s}^{2} f^{H}$ 이다.

식 (2.5)는 매도 시점에서의 내재변동성(impled volatility)을 헤지변동성으로 선택하여 델타헤지를 수 행할 때의 손익을 나타낸다. 표준 콜/풋 옵션의 경우 감마는 항상 양수이므로, 헤저의 최종 손익은 헤 지변동성 $\left(\sigma_{H}\right)$ 과 실현변동성 $\left(\sigma_{t}\right)$ 의 차이에 의하여 결정된다. 실현변동성이 헤지변동성보다 높게 형성될 때가 많을 경우 헤저는 손실을 입을 가능성이 크고, 반대의 경우는 이익을 얻을 가능성이 크게 된다. 이 외에 손익의 크기는 감마 $\left(\Gamma_{i}^{H}\right)$ 와 주가, 헤징주기 등에 영향을 받는다는 것을 알 수 있다. 헤지변동성과 실현변동성이 같을 경우 최종 헤지 손익은 거의 0이 되는데, Boyle과 Emanuel (1980)에 따르면 이 경 우 표준 콜 옵션의 헤지손익은 블랙-솔즈 가정 하에서 다음의 형태로 표현할 수 있다.

$$
P_{T}^{H}-f_{T} \approx \frac{1}{2} \sum_{i=0}^{n-1} \frac{\sigma S_{i}}{\sqrt{T-t_{i}}} \phi\left(d_{i}\right)\left(U_{i}^{2}-1\right)\left(t_{i+1}-t_{i}\right),
$$

여기서 $\phi(\cdot)$ 는 표준 정규확률밀도함수, $d_{i}=\left(\log \left(S_{i} / K\right)+\left(r+0.5 \sigma^{2}\right)\left(T-t_{i}\right)\right) / \sigma \sqrt{T-t_{i}}, K$ 는 옵션 의 행사가이고, $\left\{U_{i}\right\}$ 는 $\chi^{2}(1)$ 분포에서의 랜덤샘플(random sample)이다.

한편, 장외시장에서는 당사자들 간의 합의에 의하여 거래 성사되기 때문에 고려하고 있는 헤지변동성과 비슷한 가격으로 옵션이 매도될 수 있는 반면, 장내시장에서는 별개의 가격으로 거래되는 경우가 많다. 내재변동성이 향후 기초자산의 변동성에 대한 시장의 예측을 반영하고 있지만 개별 헤저의 예측은 시장 의 예측과 다를 수 있고, 헤저의 운용 성향과 시장을 바라보는 관점에 따라 헤지변동성이 달리 사용될 수 있기 때문에, 옵션 헤저의 실질적인 고민은 시장가격으로 옵션을 매도하였을 때 적절한 헤지변동성의 선택에 있게 된다.

옵션 매도 당시 헤저가 고려하고 있는 헤지변동성과 내재변동성이 다른 경우, 즉 시장가격으로 매도하 고 내재변동성이 아닌 다른 변동성으로 헤지를 수행하는 경우의 손익을 알아보자. $f_{0}^{i m}$ 을 옵션 매매시점 에서의 시장가(매도가)라 하고, 헤저는 고정된 헤지변동성 $\left(\sigma_{H}\right)$ 로 델타헤지를 수행한다고 하면, 최초 헤 지 포트폴리오는 $\Delta_{0}^{H}$ 개의 기초자산과 $\left(f_{0}^{i m}-\Delta_{0}^{H} S_{0}\right)$ 금액의 $\mathrm{MMF}$ 로 구성된다. 이때, $\left(f_{0}^{i m}-\Delta_{0}^{H} S_{0}\right)$ 금 액 중 $\left(f_{0}^{i m}-f_{0}^{H}\right)$ 금액은 별도의 $\mathrm{MMF}$ 에 투자하여 만기까지 유지하고, 나머지 $\left(f_{0}^{H}-\Delta_{0}^{H} S_{0}\right)$ 금액의 $\mathrm{MMF}$ 와 $\Delta_{0}^{H}$ 개의 기초자산으로 구성된 새로운 포트폴리오, $\tilde{P}^{H}$ 에 대하여 연속적인 델타헤지를 수행하 면, 식 (2.4)와 같은 방법에 의하여 다음의 최종 손익을 구할 수 있다.

$$
\begin{aligned}
P_{T}^{H}-f_{T} & =\left(f_{0}^{i m}-f_{0}^{H}\right) e^{r T}+\int_{0}^{T}\left\{d \tilde{P}_{t}^{H}-d f_{t}^{H}\right\} \\
& =\left(f_{0}^{i m}-f_{0}^{H}\right) e^{r T}+\frac{1}{2} \int_{0}^{T} \partial_{s s}^{2} f_{t}^{H}\left[\sigma_{H}^{2}-\sigma_{t}^{2}\right] S_{t}^{2} d t,
\end{aligned}
$$

여기서 $P_{0}^{H}=f_{0}^{i m}$ 이다.

따라서, 불연속적으로 델타헤지가 이루어질 경우, 헤저의 최종 근사 손익은 다음과 같이 얻어진다.

정리 2.2 주가과정 $\left\{S_{t}\right\}$ 가 식 (2.3)을 따른다고 하자. $f_{0}^{i m}$ 의 가격으로 옵션이 매도되었을 경우, 고정변동성 $\sigma_{H}$ 


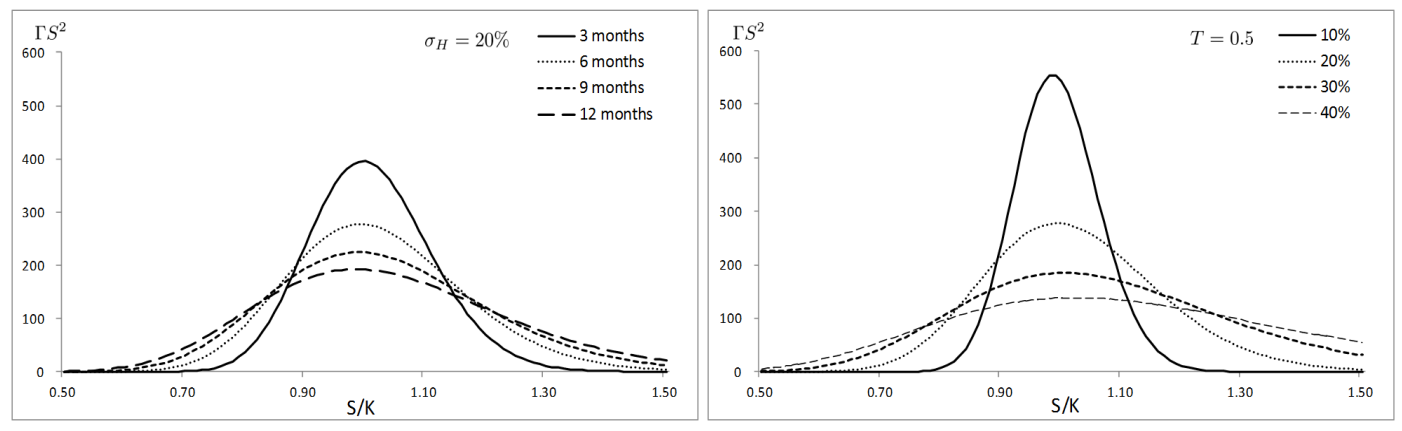

Figure 2.1. $S / K$ vs. $\Gamma S^{2}$ of an ATM call option by remaining maturities(L) and hedge volatilities(R)

로 델타헤지를 수행하는 헤저의 최종 손익은 다음과 같다.

$$
\begin{aligned}
P_{T}^{H}-f_{T} & \approx\left(f_{0}^{i m}-f_{0}^{H}\right) e^{r T}+\frac{1}{2} \sum_{i=0}^{n-1} \Gamma_{i}^{H} S_{i}^{2}\left[\sigma_{H}^{2}-\sigma_{t_{i}}^{2}\right]\left(t_{i+1}-t_{i}\right) \\
& :=\left(f_{0}^{i m}-f_{0}^{H}\right) e^{r T}+\text { Gamma P } \& \mathrm{~L} .
\end{aligned}
$$

위 정리에서 $\left(f_{0}^{i m}-f_{0}^{H}\right) e^{r T}$ 는 $\sigma_{H}$ 에만 의존하므로, 주가형태에 따른 헤지변동성 $\left(\sigma_{H}\right)$ 별 최종 손익은 결국 위 식 우변의 두 번째 항 $(\mathrm{Gamma} \mathrm{P} \& \mathrm{~L})$ 의 $\Gamma_{i}^{H} S_{i}^{2}$ 으로부터 결정되게 된다.

주가형태에 따른 표준옵션의 Gamma P\&L을 알아보기 위하여 다음의 사실을 주목하자.

$$
\Gamma_{t}^{H} S_{t}^{2} \propto \frac{S_{t}}{K} \exp \left\{-\frac{1}{2 \sigma_{H}^{2}(T-t)}\left(\log \left(\frac{S_{t}}{K}\right)+\left(r+0.5 \sigma_{H}^{2}\right)(T-t)\right)^{2}\right\},
$$

여기서 $K$ 는 옵션의 행사가이고 $\Gamma_{t}^{H} S_{t}^{2}$ 은 $S_{t} / K$ 가 $\exp \left\{\left(-r+0.5 \sigma_{H}^{2}\right)(T-t)\right\}$ 일 때 최대가 되고 이 값으로부터 멀어질수록 작아지게 된다. 예를 들어, 만기 1년 미만의 KOPSI200지수 옵션들에 대하여 $50 \%$ 미만의 헤지변동성과 $5 \%$ 내외의 무위험이자율을 고려할 경우 $\exp \left\{\left(-r+0.5 \sigma_{H}^{2}\right)(T-t)\right\}$ 의 값은 대략 0.95 에서 1.1 사이에서 형성된다.

Figure 2.1은 행사가가 100 인 $\mathrm{ATM}$ 콜옵션에 대하여 헤지변동성이 $20 \%$ 인 경우의 잔존기간별 $\Gamma_{t}^{H} S_{t}^{2}$ (좌)과 잔존기간 6 개월인 경우의 헤지변동성별 $\Gamma_{t}^{H} S_{t}^{2}$ (우)를 나타내고 있다. 그림에서 보듯이, $\Gamma_{t}^{H} S_{t}^{2}$ 은 주가가 행사가 근처에 있을 때 최대가 되며 행사가에서 멀어질수록 작아지게 되는데, 감소의 크기는 잔 존기간이 짧아지거나 헤지변동성이 작아질수록 더욱 커진다. 이는 주가가 행사가 근처에서 형성된 기 간이 길수록 최종 헤지손익에서 Gamma P\&L이 차지하는 비중은 커지게 되고, 반대로 벗어난 기간이 길수록 그 비중은 작아지게 됨을 의미한다. 이 사실을 ATM 표준옵션에 적용할 경우, 최종 헤지손익 은 잔존기간 동안 주가가 행사가 근처에서 형성될 때(횡보장)에는 Gamma P\&L에 민감하게 영향을 받 게 될 것이고, 그 외의 주가 형태일 때(추세장)에는 상대적으로 덜 받게 될 것이므로, 추세장의 경우 $\left(f_{0}^{i m}-f_{0}^{H}\right) e^{r T}$ 에서 보다 많은 이익을 취할 수 있는 방향으로, 횡보장의 경우 Gamma P\&L에서 이익을 취할 수 있는 방향으로 헤지변동성을 선택하는 것이 손익에 유리하게 될 것임을 추측할 수 있다. 일반적 으로 변동성이 작아지면 표준옵션의 이론가격도 낮아지게 되고, 따라서 $\left(f_{0}^{i m}-f_{0}^{H}\right) e^{r T}$ 은 커지게 되므 로(Figure 2.2 의 좌) 추세장에서는 낮은 헤지변동성을 사용하고, 횡보장에서는 높은 헤지변동성을 사용 하여 Gamma P\&L에서의 이익을 추구하는 것(Figure 2.2의 우)이 최종 헤지손익에 유리할 것이다. 이 에 대한 엄밀한 증명은 식 $(2.6)$ 을 $\sigma_{H}$ 로 미분하고 $S / K$ 의 범위에 따른 미분값의 부호를 조사해야하나 


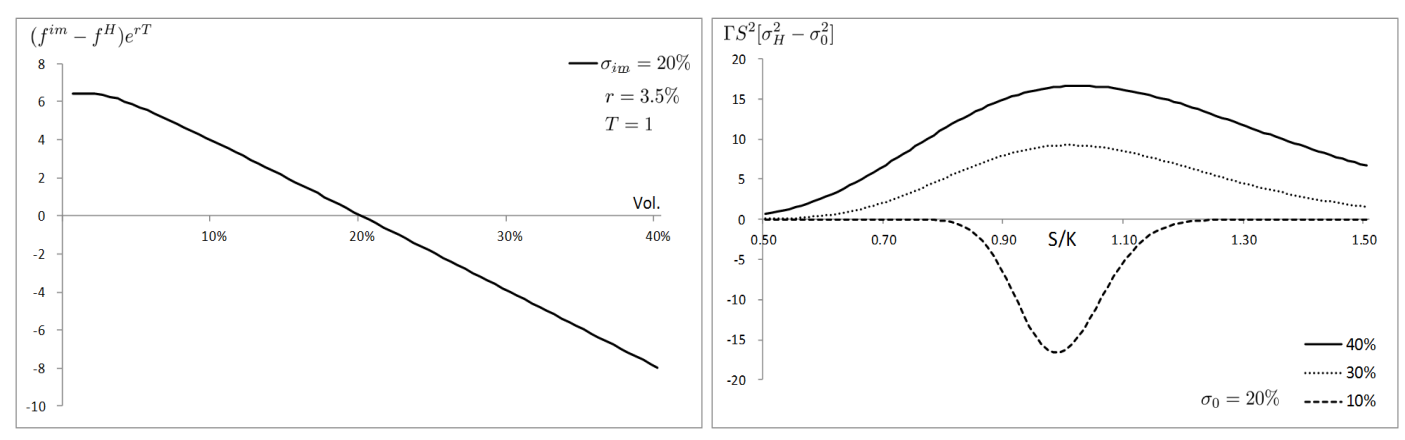

Figure 2.2. $\left(f_{0}^{i m}-f_{0}^{H}\right) e^{r T}$ when implied volatility is $20 \%(\mathrm{~L})$ and $\Gamma_{t} S_{t}^{2}\left[\sigma_{H}^{2}-\sigma_{0}^{2}\right]$ by hedge volatilities(R)
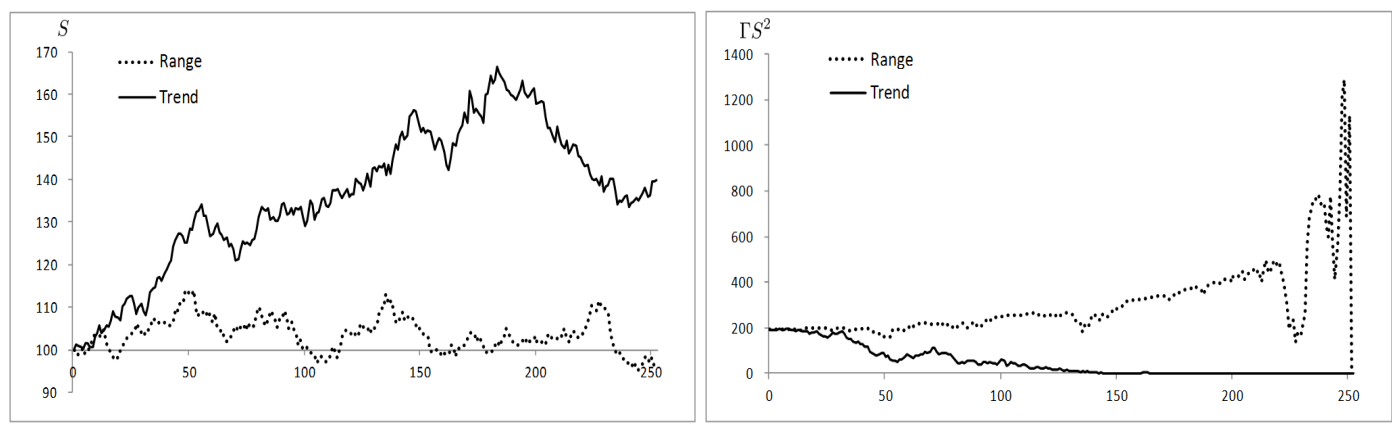

Figure 2.3. Paths of stock prices in range bound and trend(L) and corresponding $\Gamma S^{2}$ paths of an ATM call option(R)

이는 본 논문의 수준을 넘기 때문에 향후 연구로 남기고, 다음의 일례와 3 장에서의 모의실험을 통하여 이 사항을 확인하고자 한다.

Figure 2.3 은 변동성 $20 \%$ 의 GBM모형을 이용하여 횡보 형태와 상승 추세를 갖는 주가경로를 발생시킨 것이며(좌), $\mathrm{ATM}$ 표준옵션(만기 1 년, $r=3.5 \%, \sigma_{H}=0.2$ )에 대하여 각 경로에 해당하는 $\Gamma S^{2}$ 경로를 나타낸 것이다(우). 상승 추세의 주가경로에서는 시간이 흐르면서 $\Gamma S^{2}$ 의 크기가 작아지게 되는 반면, 횡보 형태의 주가경로에서는 상승추세의 경로에 비해 $\Gamma S^{2}$ 의 값이 상당히 커지게 되어 Gamma P\&L이 최종 헤지손익에 상대적으로 큰 영향을 미치게 됨을 알 수 있다. Figure 2.4 의 왼편은 Figure 2.3 의 주 가경로에 대하여 헤지변동성을 $0.5 \%$ 에서 $40 \%$ 까지 달리 하면서 구한 Gamma P\&L과 $\left(f_{0}^{i m}-f_{0}^{H}\right) e^{r T}$ 이 고, 오른편은 식 (2.6)의 근사손익과 델타헤지를 수행하여 얻은 실제 헤지손익을 나타낸다. 횡보 형태의 주가경로에서는 Gamma $\mathrm{P} \& \mathrm{~L}$ 의 기울기의 절대값이 $\left(f_{0}^{i m}-f_{0}^{H}\right) e^{r T}$ 에서의 값보다 크기 때문에 높은 변 동성을 사용할수록, 상승 형태의 주가경로에서는 반대의 상황이기 때문에 낮은 변동성을 사용할수록 최 종 손익이 유리해짐을 확인할 수 있다.

실무에서의 헤지매매에서도 이유는 다르나 위와 비슷한 전략을 종종 사용한다. 감마헤지가 이뤄지지 않 고 있는 표준옵션의 헤지매매 시, 주가가 횡보할 때는 의도적으로 감마를 작게 함으로써(높은 헤지변동 성의 사용) 잦은 손실 매매를 방지하고 추세를 형성할 때는 감마를 크게 함으로써(낮은 헤지변동성의 사 용) 추세에 따른 옵션 가격의 움직임을 빠르게 추종하는 전략이 그것이다. 이 전략은 매매 빈도를 조절 함으로써 손익을 유리하게 가져가는 반면, 앞선 내용은 매매 빈도의 조절과는 상관없다는 점에서 차이가 있다. 


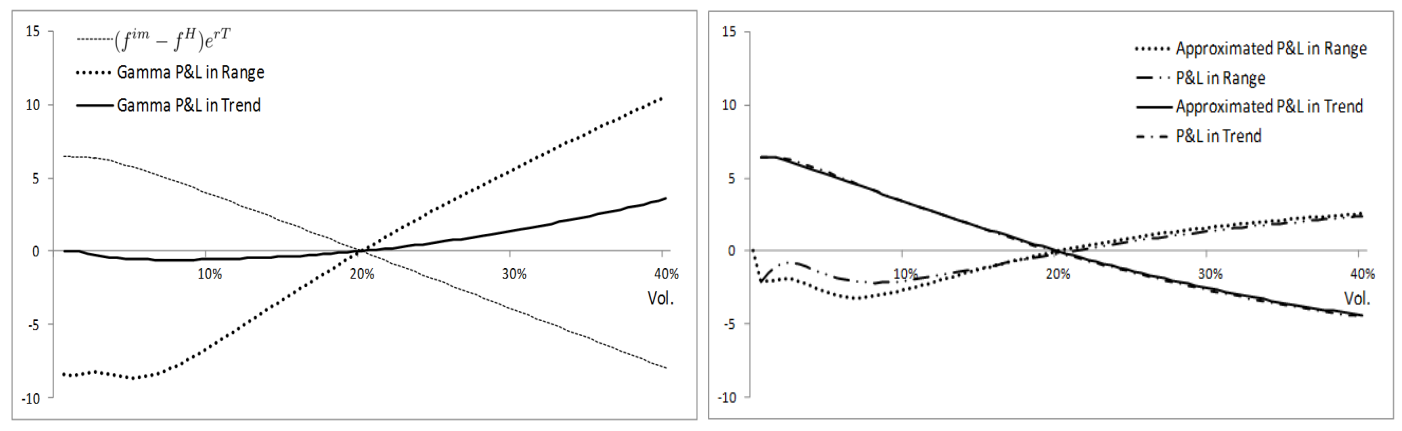

Figure 2.4. Hedge volatilities vs. Gamma P\&L and $\left(f_{0}^{i m}-f_{0}^{H}\right) e^{r T}$ of stock prices in Figure $2.3(\mathrm{~L})$ and hedge P\&L and approximated P\&L(R)

한편, ATM 또는 NTM(near-the-money) 외의 옵션에 대하여는 추세의 형태에 따라 주가가 행사가 근 방에 머무르는 기간이 다르기 때문에 위 결과를 일반화하기 어렵다. 이에 본 논문에서는 ATM 표준옵 션에 대해서만 다음 장의 모의실험을 통하여 확인하기로 한다. ATM옵션은 장내외 시장에서 거래가 가 장 활발한 옵션이기 때문에, 이에 대한 분석만으로도 실무에서의 헤지매매에 도움이 될 것으로 기대한 다.

\section{3. 모의실험}

본 장에서는 횡보, 상승, 하락, 상승 후 하락, 그리고 하락 후 상승 등 다섯 가지 주가형태와 그에 따 른 헤지변동성의 선택이 헤지손익에 미치는 영향을 모의실험을 통하여 알아본다. 횡보를 제외한 나머 지 주가형태는 추세를 가지는 경우로 구분한다. 주가는 변동성 $\left(\sigma_{t}\right)$ 이 $20 \%$ 인 식 $(2.3)$ 의 $\mathrm{GBM}$ 을 따른 다고 가정하였고, 초기 주가 $S_{0}$ 는 100 으로 설정하였다. 횡보형태의 주가경로를 생성하기 위하여, 주가 수익률의 평균이 0 이 되도록(즉, $\mu=0.5 \sigma^{2}$ ) 하였다. 하지만, 이 경우에도 추세가 나타날 수 있기 때 문에 생성된 경로의 0.5 년과 1 년 시점에서의 값이 최초 주가 대비 $90 \%$ 미만이거나 $110 \%$ 이상일 때에 는 다시 발생시켜 비교적 횡보형태에 가까운 경로가 고려되도록 하였다. 별도의 모의실험 결과, 이러 한 제거 조건 하에서 발생된 주가경로의 실현된 변동성(realized volatility)의 평균에 대한 $95 \%$ 신뢰구 간은 $19.93 \%$ 에서 $19.97 \%$ 로 의도된 변동성 $20 \%$ 와 유의한 차이가 있었으나, 그 크기가 실험 결과에 영 향을 미칠 정도는 아니기 때문에 이 차이를 무시하고 실험을 진행하였다. 상승 및 하락 형태의 경로는 식 (2.3)의 $\mu$ 를 각각 $\pm 100 \%$ 로 두고 발생시켰다. 상승 후 하락 형태는 0.5 년 시점까지는 $\mu$ 를 $100 \%$ 로, 이후에는 $-100 \%$ 로 하여 생성하였으며, 하락 후 상승 형태는 반대로 하여 발생시켰다. 각 형태별로 1000 개의 주가경로를 생성하였고, 헤지변동성을 $0.5 \%$ 에서 $40 \%$ 까지 $0.5 \%$ 간격으로 설정하여, 만기가 1 년(252영업일)인 ATM 표준 콜옵션과 풋옵션에 대하여 델타헤지를 통한 실제 헤지손익과 식 (2.6)의 근사손익을 계산하였다. 무위험이자율은 $3.5 \%$ 로 가정하였으며, 거래시점에서의 옵션은 $20 \%$ 의 변동성 으로 매도된 것으로 간주하였다. 즉, 최초 매도가는 블랙-솔즈 공식에 의하여 계산된 9.67 이 된다.

횡보와 그 외의 추세 형태의 경로에 대한 모의실험 결과가 Figure 3.1(횡보장)과 Figure 3.2에서 Figure 3.5 (추세장)에 나타나 있다. 실선과 굵은 점선은 각각 헤지변동성에 대한 최종 헤지손익과 근사손익의 평균을 나타내며, 가는 점선은 헤지손익의 $5 \%, 95 \%$ 분위수를, 대시선은 1000 개의 경로 중 수익이 발 생한 비율을 나타내고 있다. 그림에서 보듯이, 횡보와 그 외 나머지 경우에서의 결과는 반대 양상을 보 이고 있다. 횡보장에서는 높은 헤지변동성을 사용할수록, 추세장에서는 낮은 변동성을 사용할수록 초과 


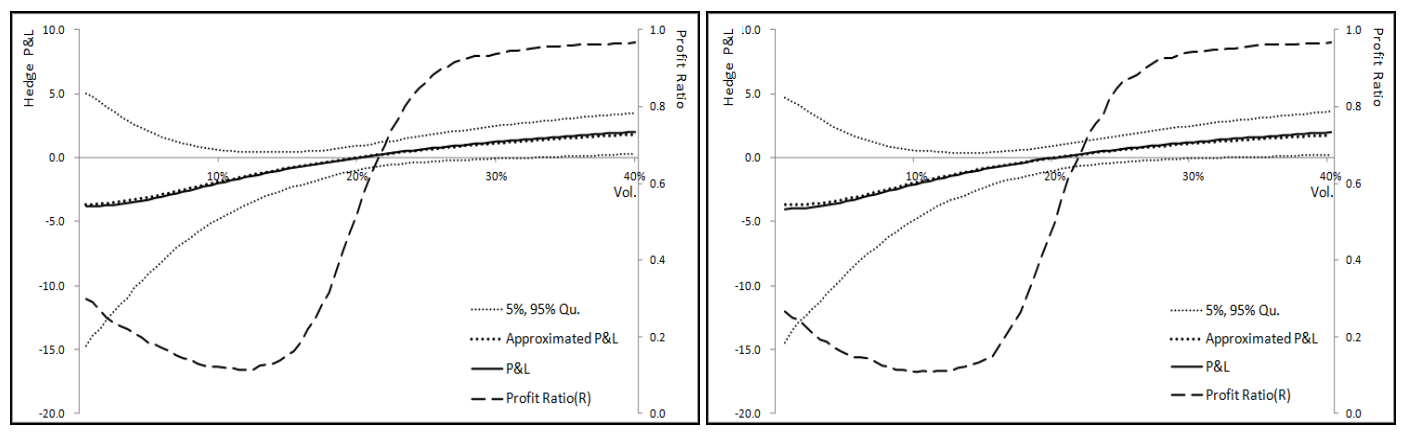

Figure 3.1. Hedge $\mathrm{P} \& \mathrm{~L}$, approximated $\mathrm{P} \& \mathrm{~L}$, and profit ratio in range bound: Call option(L) and Put option(R)

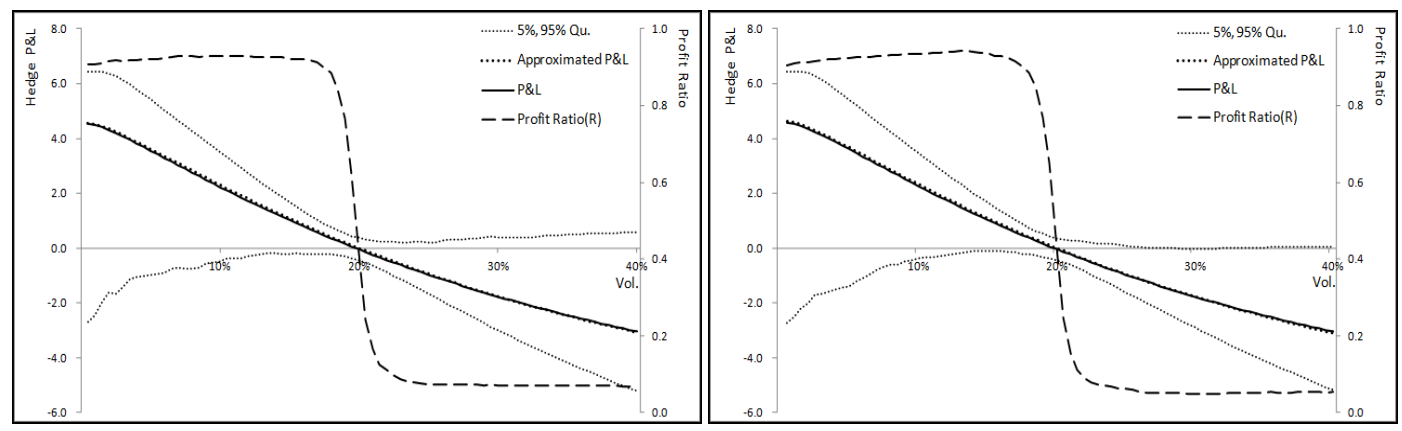

Figure 3.2. Hedge $\mathrm{P} \& \mathrm{~L}$, approximated $\mathrm{P} \& \mathrm{~L}$, and profit ratio in upward trend: Call option(L) and Put option(R)
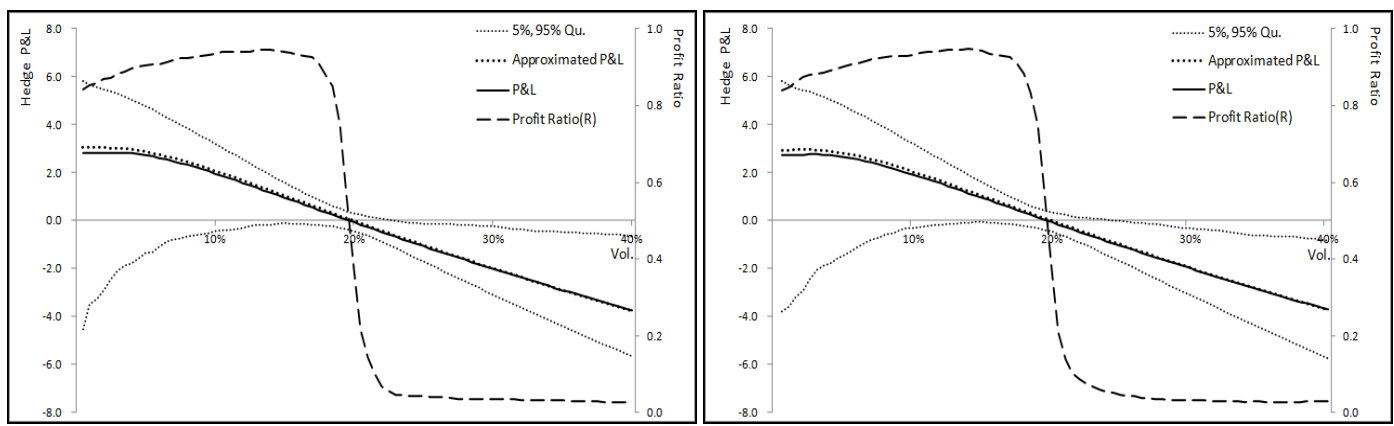

Figure 3.3. Hedge $\mathrm{P} \& \mathrm{~L}$, approximated $\mathrm{P} \& \mathrm{~L}$, and profit ratio in downward trend: Call option(L) and Put op$\operatorname{tion}(\mathrm{R})$

이익이 발생하고 있고, 헤지변동성을 반대로 사용할 경우 초과 손실이 발생하고 있음을 관찰할 수 있다. 이는 앞 장의 식 (2.6)과 (2.7)을 통하여 알 수 있듯이, 추세가 있을 경우 $\Gamma S^{2}$ 의 크기가 상대적으로 작아 지면서 나타난 결과로 해석할 수 있다. 한편, Figure 3.1에서 Figure 3.5의 대시선을 보면 수익 발생 비 율이 실현변동성 $(20 \%)$ 를 중심으로 급격하게 변하고 있는데, 헤지변동성이 실현변동성보다 너무 크거나 작지 않더라도 수익 비율이 빠르게 증가하는 것을 관찰할 수 있다.

위 실험결과를 실제 헤지매매에 활용한다면, 먼저 실현될 변동성에 대한 예측을 한 후, 추세여부에 대한 예상에 따라 예측된 변동성보다 더 높거나 작게 헤지변동성을 결정하면 될 것이다. 이때, 주가가 예상과 


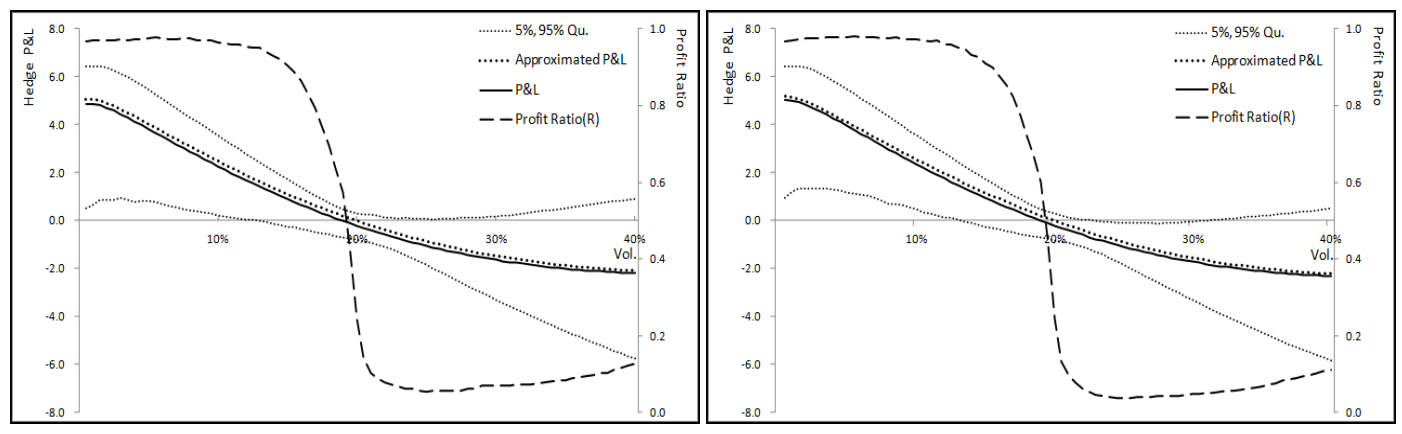

Figure 3.4. Hedge P\&L, approximated $P \& L$, and profit ratio in upward and then downward trend: Call option(L) and Put option(R)

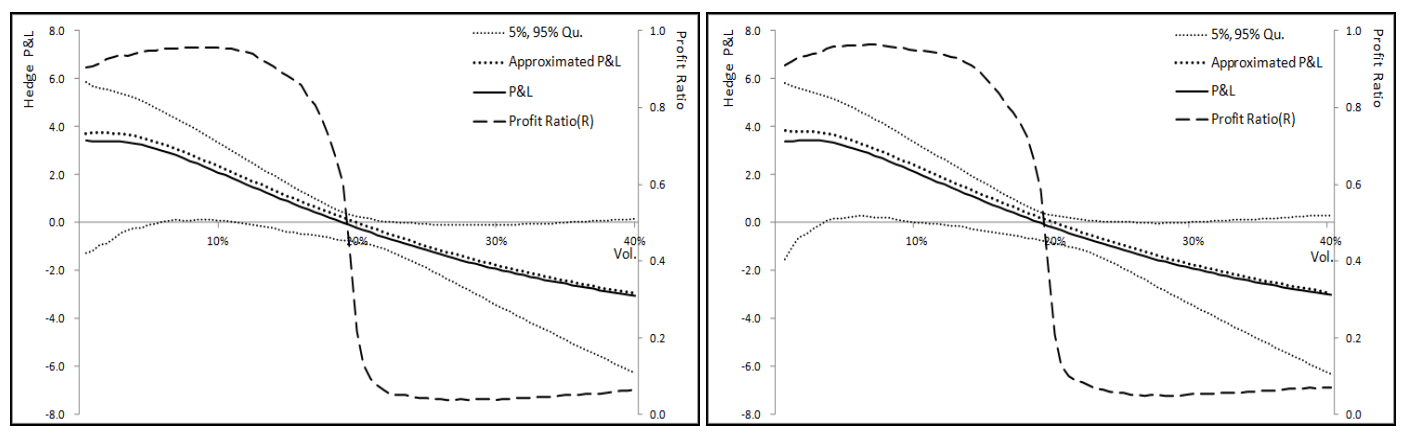

Figure 3.5. Hedge P\&L, approximated P\&L, and profit ratio in downward and then upward trend: Call option(L) and Put option(R)

는 반대로 전개될 경우 헤지변동성을 달리 선택함으로써 발생하는 손실의 크기 또한 비례해서 커지므로, 추세여부에 대한 확신의 정도나 감수할 수 있는 위험의 정도에 따라 가감의 크기를 결정해야 할 것이다.

\section{KOSPI200 자료 분석}

주가 경로의 형태에 따른 헤지변동성별 손익 형태를 KOSPI200 지수 분석을 통하여 알아보았다. 위 3 장의 모의실험 결과, 횡보를 제외한 나머지 추세의 헤지손익의 형태가 거의 비슷하였기 때문에, 본 자료분석에서는 상승 형태의 추세장을 우선 고려하였다. 분석 시기는 2009년 8월 28일부터 2010년 8월 27일까지를 횡보장으로, 2010년 7월 30일부터 2011년 8월 1일까지를 추세장(Trend1)으로 선택 하였으며, 이 기간의 시계열도는 Figure 4.1에 나타나 있다. 횡보장과 추세장에서의 주가가 GBM을 따르는지를 검정하기 위하여 로그수익률(log return)에 대한 Jarque-Bera(JB) 검정과 Anderson$\operatorname{Darling}(\mathrm{AD})$ 검정 등의 정규성 검정을 수행하였으며, 검정결과 추세장에서의 유의확률은 $0.273(\mathrm{JB}$ 검정)과 $0.164(\mathrm{AD}$ 검정)로 $\mathrm{GBM}$ 모형을 적용시키기에 무리가 없어 보이나, 횡보장의 경우 유의확률이 0.01 미만(JB 검정)과 $0.077(\mathrm{AD}$ 검정)으로 $10 \%$ 유의수준에서 귀무가설이 기각되었다. 이는 횡보 기 간 중 2009년 11월 27일 지수가 210.77에서 200.73으로 크게 하락한 시점의 영향으로 이 날을 제외 한 자료의 정규성 검정 결과를 보면 유의확률이 모두 0.1 이상이 되어, 본 분석에서는 위 횡보 기간에 도 $\mathrm{GBM}$ 모형을 적합하기로 하였다. 각 기간에 따른 검정결과 및 로그수익률에 대한 평균, 분산, 왜도 


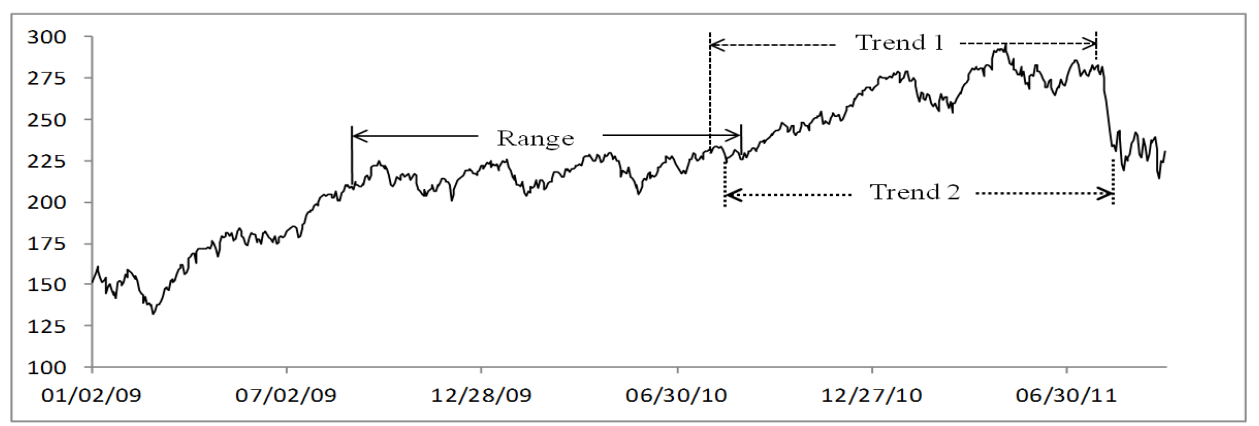

Figure 4.1. Time series of KOSPI200 index from January 2009 to September 2011

Table 4.1. Descriptive statistics for log returns and estimates of GBM

\begin{tabular}{|c|c|c|c|c|c|c|c|}
\hline & \multicolumn{5}{|c|}{ Statistics for log returns } & \multirow{2}{*}{$\hat{\sigma}$} & \multirow{2}{*}{$\hat{\mu}$} \\
\hline & mean(sd) & skewness & kurtosis & J-B test & A-D Test & & \\
\hline Range & $0.0003(0.011)$ & -0.537 & 0.961 & $22.49[0.000]$ & $0.67[0.077]$ & $17.8 \%$ & $8.8 \%$ \\
\hline Range† & $0.0005(0.011)$ & -0.281 & -0.068 & $3.35[0.187]$ & $0.47[0.247]$ & $17.1 \%$ & $13.7 \%$ \\
\hline Trend1 & $0.0008(0.010)$ & -0.237 & 0.122 & $2.59[0.273]$ & $0.54[0.164]$ & $16.1 \%$ & $22.3 \%$ \\
\hline Trend2 & $0.0001(0.011)$ & -0.604 & 0.908 & $24.49[0.000]$ & $1.46[0.001]$ & $17.8 \%$ & $3.1 \%$ \\
\hline
\end{tabular}

Range†: Presents statistics and estimates for the data except December 27, 2009.

The numbers in square brackets denote $p$-values.

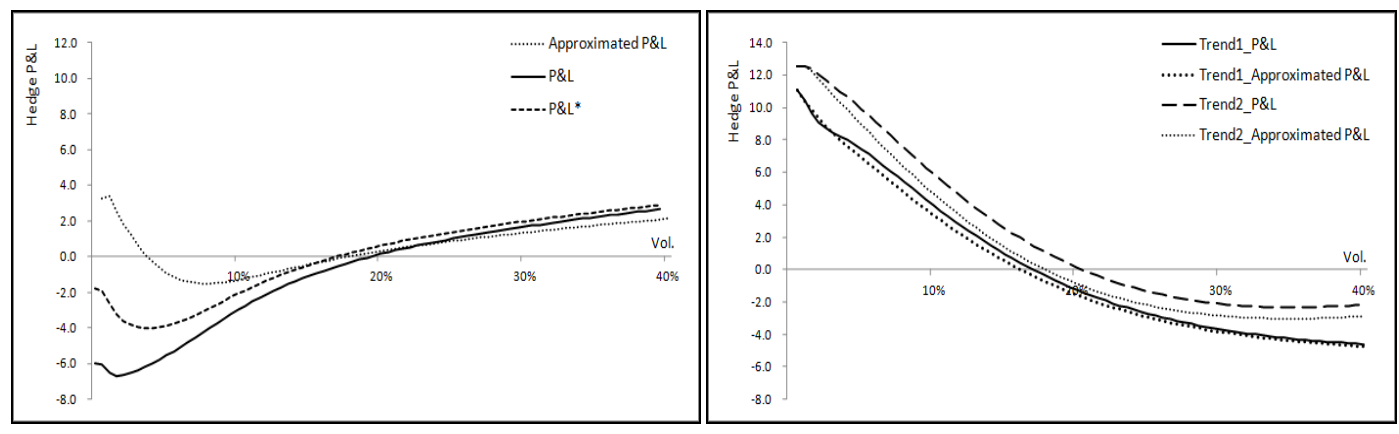

Figure 4.2. Results of KOSPI 200 analysis: Hedge P\&L and approximated P\&L in range bound(L) and trend(R)

및 첨도, 그리고 $\mathrm{GBM}$ 모수추정 결과가 Table 4.1에 정리되어 있다. 횡보장과 추세장에서의 $\sigma$ 는 각각 $17.8 \%$ 과 $16.1 \%$ 로, $\mu$ 는 각각 $8.8 \%$ 과 $22.3 \%$ 으로 추정되었다.

KOSPI200 지수에 대한 헤지손익 분석은 만기 1년인 ATM 콜옵션에 대하여 수행하였으며, 내재변동 성은 각 기간 동안에 실현된 변동성을 사용하였다. 즉, 횡보장에서는 $17.8 \%$, 추세장에서는 $16.1 \%$ 를 옵 션거래 시점에서의 시장변동성으로 간주하였고, 무위험 이자율은 $3.5 \%$ 를 적용하였다. 손익분석 결과는 Figure 4.2 에 있으며, 앞 장의 시률레이션 결과와 마찬가지로, 횡보장에서는 높은 헤지변동성을, 추세장 에서는 낮은 헤지변동성을 사용할수록 손익결과가 좋게 나타남을 확인할 수 있다.

한편, Figure 4.2 의 횡보장(좌)의 $\mathrm{P} \& \mathrm{~L}^{*}$ 는 2009 년 11 월 27 일의 지수값을 앞뒷날의 중간값으로 대체하 여 구한 헤지손익으로, 실제 헤지손익 $(\mathrm{P} \& \mathrm{~L})$ 보다 더 좋게 나타나고 있다. 이는 헤저의 포트폴리오(옵 션매도, 주식 보유, $\mathrm{MMF}$ 로 구성)의 민감도(sensitivity)가 델타 중립(delta neutral)이고 감마가 음 
수(short gamma)인 상태로, 큰 폭의 주가 하락이 있는 경우 헤지포트폴리오(주식과 MMF로 구성) 의 가격이 옵션가격의 감소분보다 더 크게 하락하면서 발생한 현상으로 해석할 수 있다. 이와 같은 손실 은 감마의 크기가 클수록 더 커지는데, Figure 4.2 (좌)에서처럼 헤지변동성이 작을수록(즉, 감마의 크기 가 클수록) 헤지손익과 $\mathrm{P} \& \mathrm{~L}^{*}$ 의 차이가 커지는데서 이를 확인할 수 있다.

마지막으로, 큰 폭의 하락이 있는 경우의 결과를 살펴보기 위하여 2010년 8월 13 일부터 2011년 8월 12 일까지의 지수(Trend2)에 대한 헤지손익을 계산하였다. 이 기간의 실현변동성은 $17.8 \%$ 이며, 수익률 에 대한 정규성 검정 결과는 모두 귀무가설을 강하게 기각시키고 있어, 이 기간에서의 주가는 GBM 모 형을 따른다고 보기 어렵다. 그리고, 이로 인하여 식 (2.6)의 근사손익과 실제 헤지손익은 추세 1 에 비하 여 상대적으로 큰 차이가 발생하고 있음을 관찰할 수 있다. 하지만, 헤지손익 결과는 위 추세장에서와 마찬가지로 헤지변동성이 작을수록 더 큰 헤지이익이 발생하고 있음을 확인할 수 있다. 한편, 큰 폭이 하락이 있음에도 헤지손익이 위 추세 1 에서 보다 좋게 나타난 이유는 추세 2 의 실현변동성이 추세 1 의 변 동성보다 커서 더 비싼 가격으로 옵션이 매도된 것으로 가정하였기 때문이다.

\section{5. 결론}

많은 경우 실무에서의 헤지 매매자는 기초자산의 과거 자료와 그 외 경제 및 시장 지표를 통해 얻은 정 보를 이용하여 미래의 실현변동성을 예측하고, 여러 가지 상황들(예를 들면, 팀 및 회사의 운용 정책과 매매자의 운용 성향 등)을 고려하여 예측된 변동성에 일정 수준의 값을 가감하여 헤지변동성을 결정한 다. 본 논문에서는 블랙-솔즈 가정 하에서 ATM 표준옵션의 델타헤지를 수행하는 경우 주가경로에 따 른 헤지변동성의 가감 방향을 제시하고자 하였다. 이를 위하여 헤지변동성과 헤지손익과의 관계를 고찰 하였으며, 모의실험과 실제 자료 분석을 통하여 그 결과를 살펴보았다.

식 (2.6)에 따르면, 델타헤지를 수행하는 경우 최종 헤지손익은 $\Gamma S^{2}\left(\sigma_{H}^{2}-\sigma^{2}\right)$ 의 값에 영향을 받는데, $\Gamma S^{2}$ 값이 주가 수준에 따라 차이가 발생하므로 동일한 헤지변동성을 사용하더라도 기초자산 가격의 경 로 형태에 따라 헤지성과가 달리 나타날 수 있음을 알 수 있었다.ATM 표준옵션의 경우 횡보장에서는 높은 헤지변동성을, 그 외의 추세장에서는 낮은 변동성을 사용할수록 손익이 유리해짐을 모의실험과 실 증분석을 통하여 확인할 수 있었다. 따라서 본 논문의 결과를 ATM 표준옵션의 헤지변동성 결정 과정 에 적용한다면, 실현될 변동성에 대한 최선의 예측을 한 후, 추세여부에 대한 예상에 따라 예측된 변동 성에 일정 값을 가감하여 헤지변동성을 결정하되, 가감의 크기는 추세여부에 대한 확신의 정도나 감수할 수 있는 위험의 정도에 따라 결정하면 될 것이다.

마지막으로, 증권사 및 은행권에서 꾸준히 발행되고 있는 주가연계증권(Equity-Linked Security, $\mathrm{ELS})$ 에 대한 연구 역시 실제적인 활용 측면에서 많은 관심을 갖게 한다. ELS는 이색옵션(exotic option)의 구조를 포함한 다양한 형태의 구조를 갖는데, 각각의 구조마다 감마의 형태와 크기가 다르기 때문에 위 표준옵션의 결과를 일반화할 수는 없다. 예를 들어, 원금비보장 Step Down형 ELS의 감마는 음수로 형성되는 기간이 많기 때문에 표준옵션과는 반대의 결과가 예상되나, Knock-Out Call ELS의 감마는 음수에서 시작하여 만기가 가까워지면서 양수로 변하는 경우가 많아 구체적인 관계를 단언하 기가 어려울 것으로 생각된다. 따라서, 상품별 헤지손익과 헤지변동성과의 관계는 주가와 만기에 따른 $\Gamma S^{2}$ 의 상태를 각각 확인함으로써 판단되어야할 것이다.

\section{References}

Black, F. and Scholes, M. (1973). The pricing of options and corporate liabilities, Journal of Political Economy, 81, 637-659. 
Boyle, P. and Emanuel, D. (1980). Discretely adjusted option hedges, Journal of Financial Economics, 8, 259-282.

Cont, R. and Tankov, P. (2004). Financial Modelling with Jump Processes, Chapman \& Hall.

Crépey, S. (2004). Delta-Hedging Vega Risk?, Quantitative Finance, 5, 559-597.

Derman, E. (2008). Dynamic Replication: Realities and Myths of Options Pricing. Available online at www.ederman.com/new/docs/smile-lecture2.pdf.

Dupire, B. (1994). Pricing with a smile, Risk, 9, 18-20.

Elder, J. (2002). Hedging for Financial Derivatives, University of Oxford, PH.D. Thesis.

Gatheral, J. (1999). Volatility and Hedging Error, unpublished manuscript. Available online at http://faculty. baruch.cuny.edu/jgatheral/hedgevolcolumbia0999.pdf.

Heston, S. L. (1993). A closed-form solution for options with stochastic volatility with applications to bond currency options, Review of Financial Studies, 6, 327-343.

Hull, J. and White, A. (1987). The pricing of options with stochastic volatilities, Journal of Finance, 42, 281-300.

Kennedy, J. S., Forsyth, P. A. and Vetzal, K. (2009). Dynamic Hedging under Jump Diffusion with Transaction Costs, Operations Research, 57, 541-559.

Primbs, J. and Yamada, Y. (2008). A new computational tool for analysing dynamic hedging under transaction costs, Quantitative Finance, 4, 405-413.

Sepp, A. (2012). An Approximate distribution of Delta-Hedging errors in a Jump-Diffusion Model with discrete trading and transaction costs, Quantitative Finance, 12, 1119-1141. 


\title{
기초자산의 추세 0 여부에 따른 헤지변동성의 결정에 관한 연구
}

\author{
구정본 $^{a} \cdot$ 송준모 ${ }^{b, 1}$ \\ ${ }^{a} \mathrm{HMC}$ 투자증권 장외파생상품팀, ${ }^{b}$ 제주대학교 전산통계학과
}

(2012년 8월 3일 접수, 2012년 12월 7일 수정, 2013년 1월 24일 채택)

\section{요 약}

본 논문에서는 기하브라운운동(geometric Brownian motion)을 기반으로 표준옵션의 델타헤지를 수행하는 경우, 헤지변동성의 선택이 헤지손익에 미치는 영향을 재탐색하였다. 이를 위하여, 헤지변동성과 헤지손익과의 관계를 고 찰하였으며, 모의실험과 실증분석을 통하여 기초자산의 추세에 따라 헤지변동성을 달리 선택하는 것이 최종 헤지손 익에 유리할 수 있음을 살펴보았다. 구체적으로, 등가격 표준옵션의 헤지매매 시 향후 기초자산이 횡보할 것으로 예 상될 때에는 헤지변동성을 상대적으로 크게, 추세가 형성될 것으로 예상될 때에는 비교적 작게 사용하는 것이 손익에 유리하였다.

주요용어: 헤지변동성, 등가격 표준옵션, 델타헤지, 감마, 헤지오차, 헤지손익.

이 논문은 연세대학교 경제대학원 금융공학 전공 구정본의 석사학위 논문임.

${ }^{1}$ 교신저자: (690-756) 제주시 제주대학로 102, 제주대학교 전산통계학과, 조교수. E-mail: jmsong@jejunu.ac.kr 